\title{
Photogrammetric Processing of UAV Imagery: Checking DTM
}

\author{
Birute Ruzgiene $^{\mathrm{a}}$, Tautvydas Berteska ${ }^{\mathrm{b}}$, Silvija Gecyte ${ }^{\mathrm{c}}$, Edita Jakubauskiene ${ }^{\mathrm{d}}$, \\ Vladislovas Ceslovas Aksamitauskas ${ }^{\mathrm{e}}$ \\ ${ }^{a, b, c, d, e}$ Vilnius Gediminas technical university, Saulètekio al. 11, 10223 Vilnius, Lithuania \\ ${ }^{a}$ Geodesy Department, Klaipeda state college, Bijūnu g. 10, 91223 Klaipéda, Lithuania
}

\begin{abstract}
The fixed-wing EPP-FPV Unmanned Aerial Vehicle (UAV) with mounted digital camera Canon S100 was used as a platform for images acquisition. Up-to-date the application of such means has increased significantly. Implemented features are low-cost, mobile and simple. Digital photogrammetric software Lisa has been used for UAV images processing and area mapping. High correctness of digital terrain model is required for the generating standard mapping products, as is orthophoto map. The quality of mapping products mainly depends on flight height, camera characteristics and ground control point's accuracy. Applying appropriate technique for digital elevation model checking, DEM errors has been determined.
\end{abstract}

Keywords: unmanned aerial vehicles; digital photogrammetry; mapping technologies; image processing; digital terrain model (DTM); orthophoto generation; accuracy evaluation.

\section{Introduction}

Before several years and up to now, the use of Unmanned Aerial Vehicles (UAV) has increased significantly. Such activity can be ascribed to technical developments of electronic components and the possibility of their integration in remotely controlled aircrafts [8].

The application of digital photogrammetry for processing of images taken using platform named UAV with integrated sensor (digital camera) is rapidly growing. There arise new terminologies - UAV Photogrammetry, UAV Images. Definition of unmanned aerial vehicles might be confused because of unmanned meaning speculation. UAV is manned platform, because of handling remotely controlled equipment, but without a pilot sitting in the platform. It seems that definition of Remotely Operated Aerial Vehicles (ROAV) would be more acceptable.

UAV photogrammetry opens various new applications in the close range domain, combining aerial and terrestrial photogrammetry. It is a new near real time application and low-cost alternatives to the classical manned aerial photogrammetry [1]. Main features of UAV Photogrammetry are considered with respect on costs (low-cost), flying altitude (low-high), capability of image acquisition in real-time that's quality depends on sensors features, flight performance (e.g., flying speed $50-60 \mathrm{~km} / \mathrm{h}$ ), influence of atmospheric and environment conditions, wind influence, etc. Different types, classification, categorization of UAV's, applied for photogrammetric data acquisition are used [11].

The interest of UAV great potential for digital photogrammetry application is rising in many countries, as well as in Lithuania. Up-to-now there main fields of UAV application are the acquisition of cadastral area overlook images or for publicity needs.

Digital photogrammetric methods are applied for generation of digital terrain model of the Earth's surface and digital aerial images geometry correction [6]. The digital terrain model should be created in required quality for getting qualitative mapping production using digital images of Earth surface [9].

The aim of research is to analyze UAV photogrammetric performance for collecting images and, applying appropriate techniques, to check the digital elevation model, generated from UAV imageries.

Corresponding author: Birute Ruzgiene. E-mail address: birute.ruzgiene@vgtu.lt

http://dx.doi.org/10.3846/enviro.2014.242

(C) 2014 The Authors. Published by VGTU Press. This is an open-access article distributed under the terms of the Creative Commons Attribution License, which permits unrestricted use, distribution, and reproduction in any medium, provided the original author and source are credited. 


\section{Technical means and image data processing}

The fixed-wing UAV platform, the model EPP-FPV (see Fig. 1) was used for experimental image data acquisition [4].

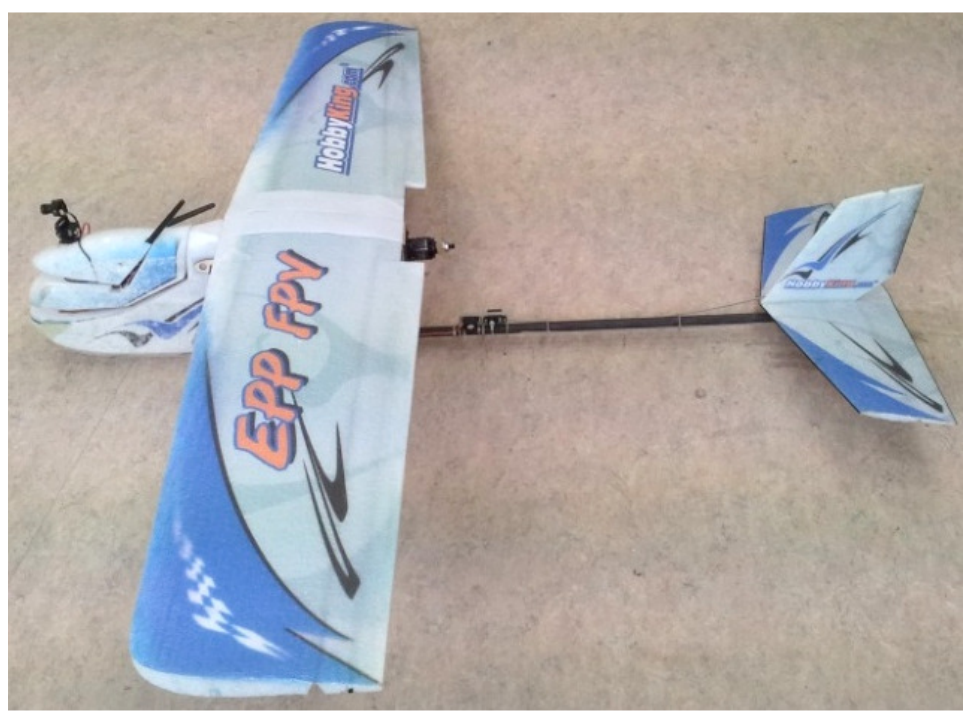

Fig. 1. Unmanned aerial vehicle used as platform for acquisition of images

The EPP-FPV foam construction with a wingspan of 1.8 meters and a take-off weight around $4 \mathrm{~kg}$ makes it a robust, low cost, low weight UAV platform. The UAV has a cruising speed of about $14 \mathrm{~m} / \mathrm{s}$ and is able to fly up to 30 minutes on low wind conditions. Therefore, it can cover a flight distance of roughly $30 \mathrm{~km}$ after subtracting some reserves for climbing and landing. Flight altitude can be very diversely, but is better of $150 \mathrm{~m}$ to $300 \mathrm{~m}$, obviously of needed images resolution.

The platform guidance can be fully automatic, semi-manual or manual. Take off is automatic or manual, landing on flat surface is automatic or manual. Autopilot Ardu Pilot Mega (APM) is used for automatic guidance. It's based on the Arduino embedded system. Flight plan programme Mission Planner, installed in computer, allows simple and fast guidance of the automated flight.

The UAV can be commanded by a PC based ground station which connected via RF link [5]. Automatic flight needs gyroscope, three axis acceleration meter, pressure sensor, air velocity sensor, $10 \mathrm{~Hz}$ GPS module, battery voltage sensor, $4 \mathrm{Mb}$ memory chip, integrated flight parameter storage and a telemetry module [3].

Images have been taken with high resolution consumer camera Canon S100. Camera's nominal focal length is of $5.2 \mathrm{~mm}$. Some cameras feature:

- A 1/1.7" CCD sensor, incorporated with 12.1 Mega pixels.

- Integrated GPS module, that's allows to determine the geodetic coordinates of each image projection centre during the flight.

- Maximum images frame size is $4000 \times 3000$ pixels.

The camera was mounted under airframe. Before flight camera is turn on, focus and focal length is determined. The $A r d u$ Pilot can operate not only UAV, but also other equipment on the platform. Autopilot system is managing camera exposition, therefore, image collection is fully computer assisted. Obtained high resolution images can be used for processing in photogrammetry application [10].

The standard workflow is accepted for image data acquisition:

- Determination of project parameters.

- Flight planning.

- Autonomous photogrammetric flight.

- Quality check of the data.

- UAV block triangulation.

- Generation of digital surface model, creation of orthophoto, 3D modelling.

During one autonomous photogrammetric flight, the camera, mounted at UAV platform, can collect hundreds of images.

For autonomous flight was used autopilot board and PC programme „Mission Planer“. This application is software, which allows seeing in monitor a map, for example, from Google Earth, which is required for planning of flight and signifying waypoints. It helps controlling autonomous triggering of images, autonomous take-off and landing.

The producer proposed the following „Mission Planer" feature:

- Point-and-click waypoint entry, using Google Maps application.

- Select mission commands from drop-down menu.

- Download mission $\log$ files and analyse them.

- Configure autonomous photogrammetric flight settings for airframe.

- Interface with a PC flight simulator to create a full hardware-in-the-loop UAV simulator. 
- See the output from autonomous photogrammetric flight's serial terminal.

Important features of the quality data checking is image resolution, clearly and tilts. After landing, collected images are checked, camera SD card is inserted in PC for loading images, if required, a flight is repeated. All jobs proceed in real time in the field.

Experimental fly using UAV, EPP-FPV with equipped camera Canon $S 100$ was executed by employers from Space science and technology institute, Lithuania. The very high requirements for fly realisation did not apply. The aim was to realise short fly and collect images. Planning of flight there was important to pay attention on good weather, still wind and optimal altitude.

UAV flight was executed over the area of Naujakiemis, region of Vilnius. The flight area (about 80 ha) was chosen purely accidentally. No different geomorphologic landforms were specially chosen. The site was partly flatland, where mean altitude is approx. 125 meters. The use of images for photogrammetric processing and for capture of 3D data was intended.

After the manual take-off and check of the fixed-wing parameters, the flight mode was changed to the automated flying mode. When UAV take-off achieves selected high, it began taking images. The UAV flight was controlled with telemetry module; therefore, density of waypoints was major near telemetry module. The flight strip did not look as not standard (not usual) (see Fig. 2). The flight strips were generated as polygons of path and involves six polygons with collected 184 images.

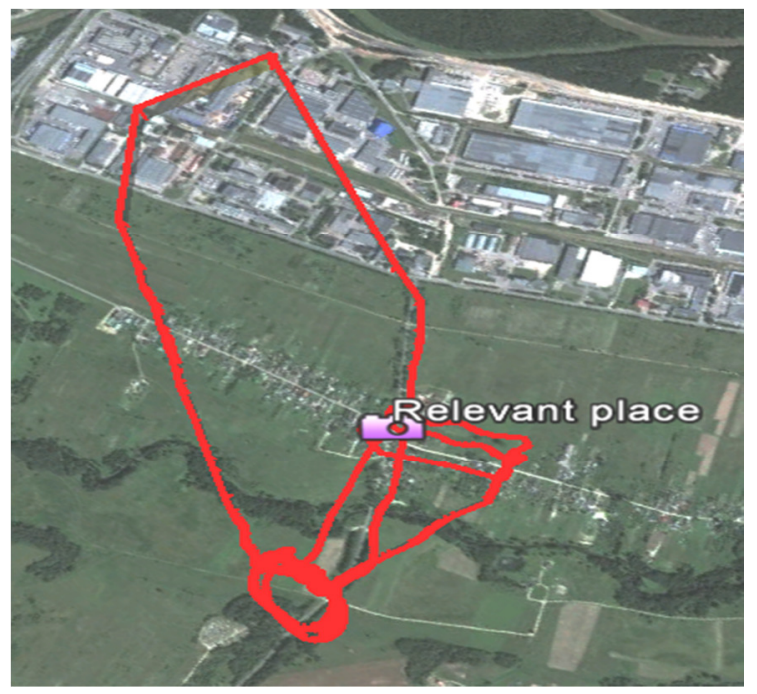

Fig. 2. UAV flight plan and area

The flight was performed at a height of approx. $150 \mathrm{~m}$ above ground in order to capture images at a ground sample distance $(\mathrm{GSD})$ of up to $10 \mathrm{~cm}$. GSD $=\mathrm{CCD}$ pixel size $* \mathrm{H} / \mathrm{c}$, where $\mathrm{H}-$ flying height, camera focale length $\mathrm{c}=35 \mathrm{~mm}$, $\mathrm{CCD}$ pixel size $=3 \mu \mathrm{m}$.

Photogrammetric processing of images. Most software packages can process the UAV images. UAV block triangulation (images orients and generates by the navigation unit of the UAV) leads to a reduction of the number of control points required for the orientation. The professional photogrammetric software packages used for DSM, orthophoto, 3D models generation. Photogrammetric processing software categorizes into classes based on their capability for processing of aerial, terrestrial and a combination of aerial and terrestrial data. Processing the UAV data needs evaluation of a selected software packages and usage for applications.

Image pair has been selected for experimental investigations (c.f. Fig. 3).

The photogrammetric software package version of $L I S A$ has been used for image processing [2]. The package is divided into modules: LISA BASIC, FOTO, BLUH and FFSAT. The modules LISA BASIC and FOTO were used for experiment. LISA BASIC module is raster GIS software with numerous possibilities for image processing, terrain modelling, etc. LISA FOTO is extension of LISA BASIC - a small digital photogrammetric workstation. The software package is of versions with slightly reduced functionality: the maximum size per image is limited to $10 \mathrm{MB}$, only grey scale (not colour) images can be processed, and the tools to create and handle a data base for geocoded images are not available.

The ground control points (GCPs) for exterior images orientation have been selected points/features well identified in the images, and their coordinates were determined by geodetic measurements. For getting the best results of exterior images orientation, and because images from UAV are significantly under tilt, as many ground control points as possible are required (15 GCPs were used). 

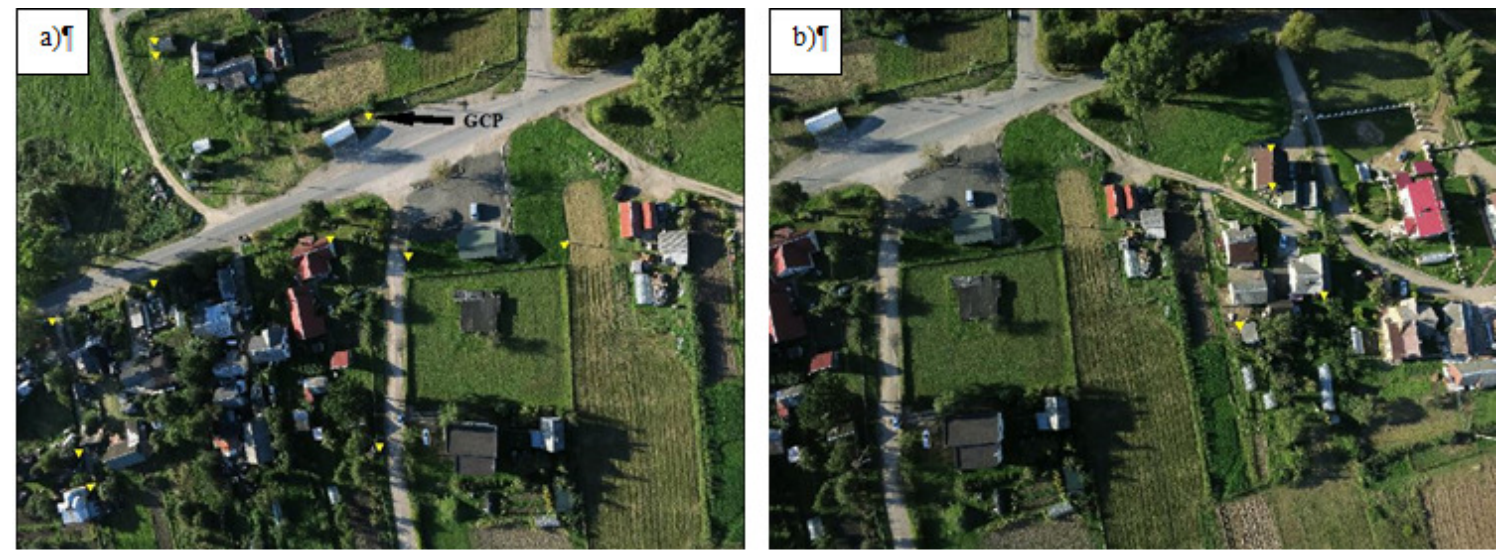

Fig. 3. Stereo pair (left and right images) selected for photogrammetric images processing and GCPs distribution on the test area: a) on the left image; b) on the right image. $\nabla-$ GCP

The results from UAV images exterior orientation are presented in Figure 4. The maximal residual in $\mathrm{x}$ and $\mathrm{y}$ coordinates for left image orientation is $0.073 \mathrm{~mm}$ referring to the image and the standard deviation is $0.055 \mathrm{~mm}$; and for the right image $-0.158 \mathrm{~mm}$ and $0.084 \mathrm{~mm}$ respectively. Images resolution is $180 \mathrm{dpi}(141.1 \mu \mathrm{m})$. Received residuals after exterior orientation are approx. of half a pixel.
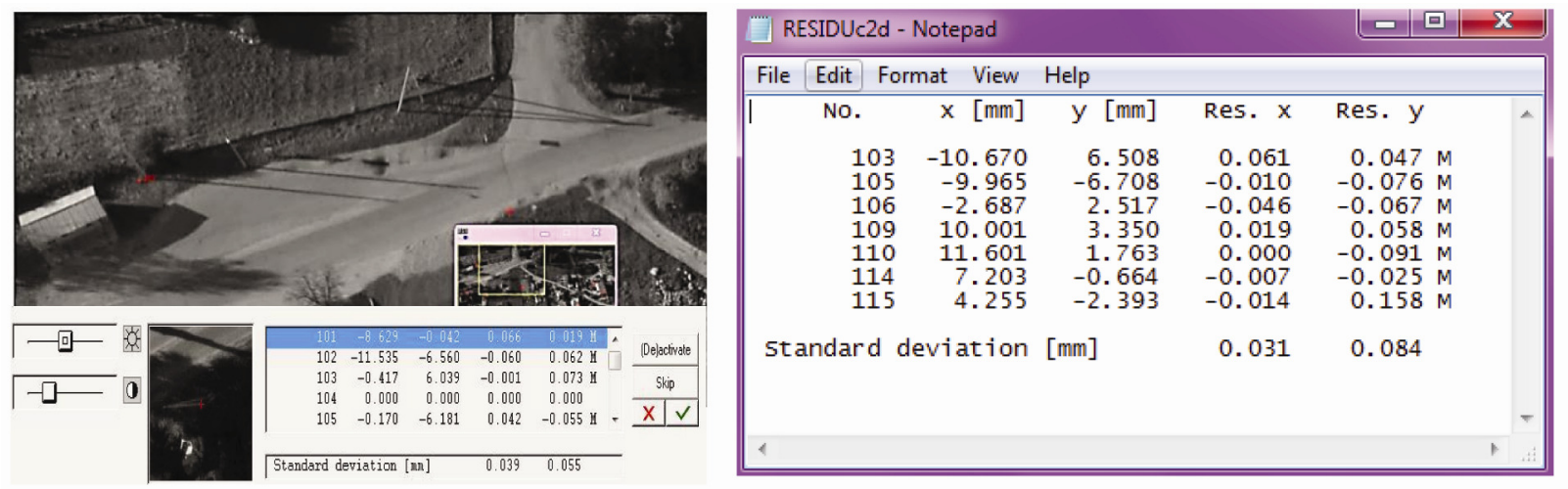

Fig. 4. Exterior orientation results of left and right images

The orthophoto was generated with overlaid contour lines (interval $5 \mathrm{~m}$ ). The orthophoto image covers about $35000 \mathrm{~m}^{2}$ area.

\section{Checking of digital terrain/elevation model}

Digital surface (situation) model (DSM) contains height values at the top of objects on the terrain and needs for generation of orthophoto images. Digital terrain model (DTM) or digital elevation model (DEM) contains height values of terrain and needs for representation of relief. DTM quality control involves interior and exterior accuracy. Interior accuracy can be defined by stereo measurements. Exterior accuracy - comparison created DTM's terrain point elevation with data from geodetic or GPS measurements.

Approx. accuracy of point's heights is 0,001 of flying height. Horizontal accuracy $S x=S y \sim 1 / 3$ of GSD. Vertical accuracy $S z=H / b * S x$.

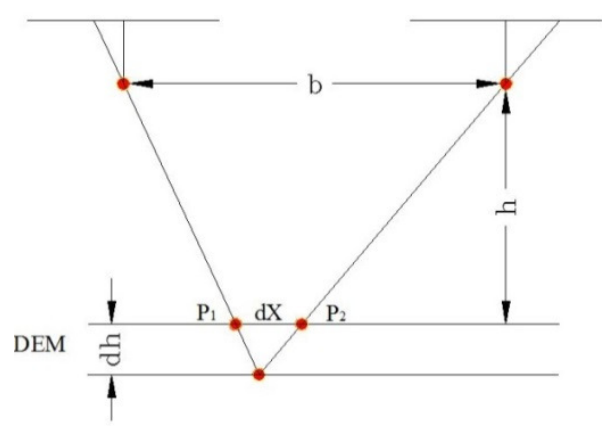

Fig. 5. Principle diagram for checking of digital elevation model 
The DEM can be improved when the measured height errors $(d h)$ are determined and used as corrections [7]. Principal diagram for DTM checking is presented in Figure 5.

The errors of height in DTM are calculated using the following formula:

$$
d h=p_{x} \frac{h}{b}
$$

where $p_{x}$ - parallax between two images;

$h$ - point height in DEM, $h=Z_{01}-Z_{D E M}$;

$Z_{01}$ - elevation of left image projection centre;

$Z_{D E M}$ - elevation of DEM point;

$b$ - photo base.

Generated DEM (one dataset) from UAV images have been checked using formula (1).

Automatically from generated DTM 3D points coordinates have been imported regarding to measured 2D points coordinates using created orthophoto map.

Selected points for heights control was measured stereoscopically. Fragment of results from stereoscopic measurements is presented in Figure 6. Results obtained approx. the same as from DTM generated automatically using image matching technique.

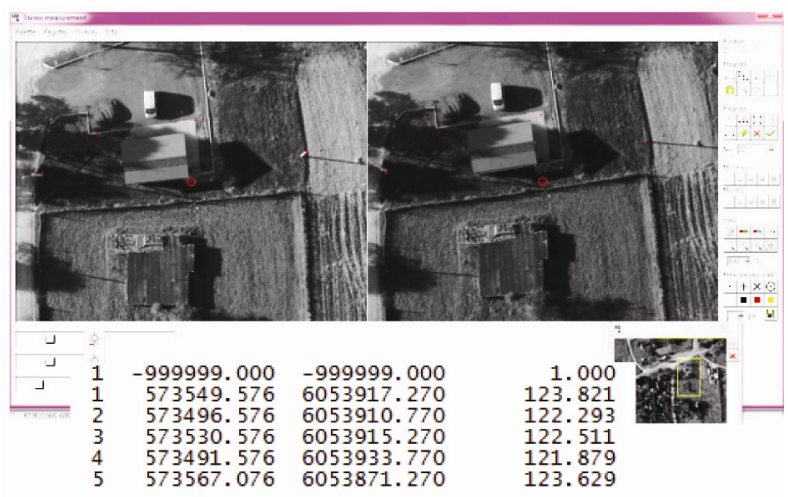

Fig. 6. Fragment of results from stereoscopic measurements

DEM evaluation results are presented in Figure 7. Maximal height error $d h$ is $0.55 \mathrm{~m}$. Generated terrain model should be corrected regarding determined height errors.

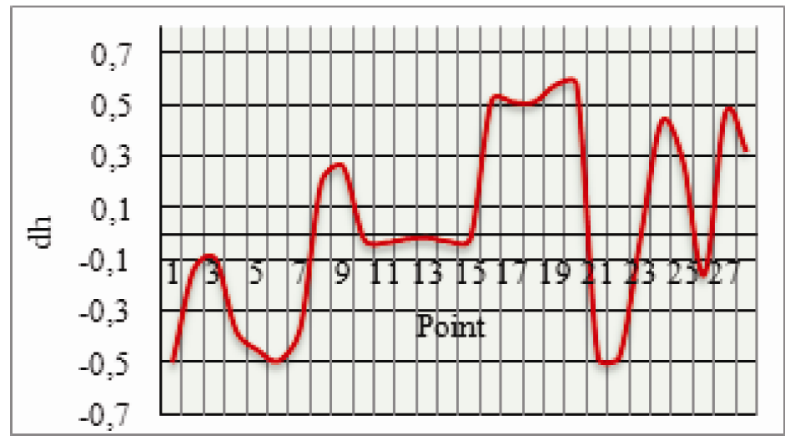

Fig. 7. Determined errors of DEM height points

\section{Conclusions}

UAV Photogrammetry, getting images from bird fly, provides low cost, small area, prompt data collection used for image processing. Autopilot system guarantees correct fly, cameras triggered auto-control.

The UAV flight strips over experimental area were generated as polygons of path (see Fig. 2) - not straight patches as requires traditional aerial photogrammetry. UAV fly had significant dependence on wind and vehicle was under the considerable tilt. Because of that upraises the demand for checking correctness of photogrammetric production elaborated from UAV images.

UAV images are aerial and, either terrestrial, because of vehicle's low-flying. So, it is important to selected and evaluate suitability of software packages used for UAV data processing and advantage in applications. The photogrammetric software LISA, used for image processing, represents small, but powerful Digital Photogrammetric Workstation. However, some 
limitation (image size, only grey scale images) reduced functionality of image processing and influenced the results. By using other software such as Pix4D (rapidly expanding in photogrammetric communities [12]) for UAV images processing and cartographic data collection the photogrammetric data analysis could be improved and speed up results.

Evaluation of DEM, generated from UAV images, demonstrates relevancy of digital elevation model correction aiming for a high accurate mapping product. Generated DEM from UAV images have been checked. Maximal height error $d h$ is defined $0.55 \mathrm{~m}$.

Evaluation of DEM, generated from UAV images, demonstrates relevancy of digital surface model correction aiming for high accurate mapping product. As well as, because of significant oblique UAV images needs the special designed images processing software for digital terrain model creation and orthophoto production with desirable 5-10 cm resolution.

\section{References}

[1] Eisenbeiss, H. 2009. UAV photogrammetry. ETH Zurich, Switzerland, Mitteilungen, p. 235.

[2] Linder, W. 2009. Digital Photogrammetry. Springer-Verlag, Berlin, Heidelberg, p. 220. http://dx.doi.org/10.1007/978-3-540-92725-9

[3] Rudinskas, D. 2011. Bepiločiu orlaiviu skrydžio parametru matavimu duomenu perdavimo saugos metodikos sukūrimas. Daktaro disertacija. Vilniaus Gedimino Technikos Universitetas. Vilnius: Technika. 85 p.

[4] Berteška, T.; Ruzgiene, B. 2013. Photogrammetric mapping based on UAV imagery, Geodezija ir Kartografija [Geodesy and Cartogrpahy] 39(4): $158-163$.

[5] Haala, N.; Cramer, M.; Weimer, F.; Trittler, M. 2011. Performance Test on UAV-Based Photogrammetric Data Collection in International Archives of the Photogrammetry, Remote Sensing and Spatial Information Sciences Vol. XXXVIII-1/C22, Zurich, Switzerland: 1-6.

[6] Haala, N.; Hastedt, H.; Wolf, K.; Ressl, C.; Baltrusch, S. 2010. Digital Photogrammetric Camera Evaluation - Generation of Digital Elevation Models, PFG 2/2010: 99-115.

[7] Norvelle, F. R. 1996. Using Iterative Orthophoto Refinements to Generate and Correct Digital Elevation Models. Digital Photogrammetry, an Addendum to the Manual of Photogrammetry, ASPRS, ISBN 1-57083-037-1, 151-155.

[8 Rock, G.; Ries, J. B.; Udelhoven, T. 2011. Sensitivity analysis of UAV-photogrammetry for creating digital elevation models (DEM) in International Archives of the Photogrammetry, Remote Sensing and Spatial Information Sciences Volume XXXVIII-1/C22: 69-73.

[9] Ruzgienè, B. 2010. Skaitmeninio reljefo modelio kūrimo metodai ir tikslumo tyrimas, taikant skaitmeninès fotogrametrijos technologija, Geodezija ir Kartografija [Geodesy and Cartogrpahy] 36(2): 57-62.

[10 Sužiedelytė-Visockienė, J.; Bručas, D. 2009. Digital photogrammetry for building measurements and reverse-engineering, Geodezija ir Kartografija [Geodesy and Cartogrpahy] 35(2): 61-65.

[11] UAV Systems-Unmanned Aerial Photography. AUVSI [viewed on March 22, 2013]. Available on Internet: http://www.uavsystems.com.au/

[12] Pi4D [viewed on January 10, 2014]. Available on Internet: http://pix4d.com/ 